\title{
ВОЗРАСТНАЯ ДИНАМИКА СОДЕРЖАНИЯ ПИХТОВОГО МАСЛА В ДРЕВЕСНОЙ ЗЕЛЕНИ ABIES SIBIRICA. ТЕОРЕТИЧЕСКИЕ АСПЕКТЫ ОЦЕНКИ
}

\author{
(C) С.В. Уианов, Р.А. Степень, В.М. Ушанова" \\ Сибирский государственный технологический университет, пр. Мира, 82, \\ Красноярск, 660049 (Россия), e-mail: ushanova_vm@mail.ru
}

Оценена изменчивость содержания эфирного масла в древесной зелени пихты сибирской в девяти возрастных группах. Показано, что за исключением подроста его количество от молодняков к перестойным древостоям снижается вдвое. Содержание в эфирном масле борнилацетата, который определяет качество и стоимость продукта, уменьшается с 34 до 24 \%. При изменении широты произрастания пихты сибирской (от Красноярской лесостепи к Лесосибирской тайге) его содержание в древесной зелени возрастает. Установлено существенное изменение содержания эфирного масла в охвоенных побегах по высоте кроны дерева. Его количество в верхней части кроны в 1,5 раза выше по сравнению с нижней частью. Предложена зависимость для оценки содержания эфирного масла в древесной зелени охвоенных побегов по высоте кроны. Получена адекватная модель возрастной динамики изменения содержания эфирного масла в охвоенных побегах, позволяющая оценить вклад и характер убывания эфирного масла в ассимиляционном аппарате пихты сибирской в возрастном интервале от 0 до 200 лет. Проведена параметрическая идентификация модели для пихты, произрастающей в Красноярской лесостепи и Лесосибирском регионе. Максимальное содержание эфирного масла соответствует пихте сибирской возраста от 25 до 30 лет с последующим снижением до минимума у перестойных деревьев.

Ключевые слова: пихта, возраст, древесная зелень, эфирное масло, математическое моделирование, статистические испытания.

\section{Введение}

Располагая огромными лесными богатствами, Российская Федерация существенно уступает многим странам по их отдаче. Вклад нашей страны в мировом объеме продукции составляет 0,3\% [1]. При переработке деревьев хвойных пород недостаточно полно используется их наиболее ценная часть - древесная зелень. Вместе с тем, согласно проведенным расчетам, экономический эффект при ее комплексном использовании на порядок выше отдачи от стволовой части [2-15]. Однако в настоящее время такая переработка в связи с низкой востребованностью ее продукции реализована только на северо-западе страны. Значительный спрос, в том числе и за рубежом, получило эфирное масло. В России его полупромышленное производство налажено в Сибири из охвоенных побегов пихты сибирской (Abies sibirica Ledeb), где находятся ее большие массивы. Для эффективного развития этой лесохимической отрасли важно оптимизировать про-

Уианов Сергей Викторович - кандидат технических наук, доцент, заведующий кафедрой высшей математики и информатики, e-mail: ushanov_sv@mail.ru Степень Роберт Александрович - доктор биологических наук, профессор кафедры промышленной экологии, процессов и аппаратов химических производств, e-mail: stepen.rob@yandex.ru

Ушанова Валентина Михайловна - доктор технических наук, профессор кафедры промышленной экологии, процессов и аппаратов химических производств, e-mail: ushanova_vm@mail.ru изводство пихтового масла. Проведены значительные исследования по изучению влияния на его выход технологических факторов и найдены оптимальные условия выделения. В меньшей мере изучено влияние на выход пихтового масла биоценотических факторов [2-5, 7-9].

Цель работы: изучение влияния на содержание эфирного масла в древесной зелени Abies sibirica $L d b$. одного из основных биоценотических факторов - возраста деревьев и связанного с ним

\footnotetext{
* Автор, с которым следует вести переписку.
} 
распределения охвоенных побегов по высоте дерева, а также разработка математической модели, описывающей эту зависимость.

\section{Экспериментальная часть}

Эфирное масло из древесной зелени пихты, как правило, отгоняется острым водяным паром $[2-5,7$, $8,15]$. Определяющими при его получении считаются технологические факторы, основными из которых являются продолжительность процесса, измельчение сырья, температура и скорость подачи пара. Их оптимизация позволяет увеличить выход масла в два раза и более. Не меньшее влияние на повышение его выхода оказывают и биоценотические показатели $[3-5,9]$. Однако на них, в том числе и на возраст древостоев, обращается мало внимания. В некоторых работах даже не приводится их класс возраста.

Практически единственным сырьем, используемым для получения эфирного масла как целевого продукта, является древесная зелень Abies sibirica Ldb. Отбор образцов проводили в течение ряда лет в сентябре-октябре, в период подготовки пихты к состоянию покоя, когда охвоенные побеги наиболее богаты эфирным маслом. При проведении экспериментов образцы отбирали в средней части кроны 10 нормально развитых деревьев 1-8 классов возраста. В первом из них помимо молодняков делали отбор и у подроста. Для достоверности результатов отбор проводили в западной (около 80 км от Красноярска) и восточной (70 км) частей Красноярской лесостепи. В лабораторных условиях пробы (с диаметром в отрубе 10 мм) измельчали, усредняли и определяли влажность. Эфирное масло из древесной зелени каждого из участков в двукратной повторности отгоняли в аппаратах Клевенджера. Его содержание находили волюмометрическим способом, обеспечивающим циркуляцию флорентинной воды $[5,16]$. Выход масла рассчитывали на абсолютно сухую массу сырья. Его анализ проводили на хроматографе ХРОМ 5 с набивной колонкой в изотермическом режиме (при $135^{\circ} \mathrm{C}$ ) с неподвижной фазой динонилфталатом (5\%) на хроматоне с использованием пламенно-ионизационного детектора.

Обработка экспериментальных данных проводилась общепринятыми в математической статистике методами [17-18]. Параметрическая идентификация модели выполнялась нелинейным методом наименьших квадратов [19-20]. Оценки доверительных интервалов изменения коэффициентов модели и расчетных значений определялись методом статистических испытаний с выполнением 10000 компьютерных имитационных экспериментов [21].

\section{Обсуждение результатов}

Онтогенетическое развитие существенно сказывается на динамике всех компонентов растения, прежде всего ассимиляционного аппарата. Это относится и к сумме содержащихся в ней летучих терпеноидных соединений - эфирному маслу. Результаты определения его содержания в древесной зелени исследованных возрастных групп приведены в таблице 1.

Начиная с молодняков, содержание эфирного масла в древесной зелени с увеличением возраста деревьев монотонно убывает. Так, в охвоенных побегах молодняков и жердняков его вклад вдвое выше, чем у спелых и перестойных древостоев. Такая закономерность свойственна и древесной зелени пихты северной тайги [22]. Кроме того, в ходе онтогенеза в пихтовом масле снижается содержание борнилацетата, определяющего его качество и ценность. Если в масле охвоенных побегов молодняков на него приходится $32-34 \%$, то у спелых древостоев в среднем $27 \%$, а у перестойных - до $24 \%$. Отсюда очевидно, что в пихтоваренном производстве предпочтительным сырьем служат охвоенные побеги первых двух классов, хотя это серьезно ухудшает использование их биомассы в других отраслях.

Такая закономерность наблюдается и у других основных хвойных лесообразующих пород Сибири со сравнительно высоким содержанием терпеноидов в древесной зелени - кедре сибирском [9] и сосне обыкновенной $[23,24]$. Основной причиной обеднения эфирным маслом при старении, по-видимому, является изменение условий протекания метаболизма в хвое, уходящей в тень в процессе роста растений. Известно, что в онтогенезе Abies sibirica Ldb увеличивается количество крупных и снижается число мелких ветвей бедных терпеноидами [25]. Экспериментально установлено, что вклад масла существенно возрастает с уменьшением диаметра побега пихты [4].

Учитывая общность характера возрастной динамики содержания эфирного масла в древесной зелени хвойных пород, представляется важным оценить состоятельность найденной зависимости. Начальной стадией служила оценка влияния индивидуальной изменчивости на результаты исследования. Эксперименты 
показали значительный разброс содержания масла в охвоенных побегах индивидуальных деревьев одного класса возраста.

На рисунке 1 представлены эмпирическая (по данным для 20 деревьев) и теоретическая (нормальная) интегральные функции распределения пихтового масла в охвоенных побегах отдельных деревьев молодняка пихты. Проверка гипотезы нормальности эмпирического распределения критерием согласия Фроцини [17] показала, что она не отклоняется при 5\% уровне значимости (расчетное значение критерия Фроцини $(0,121)$ меньше критического значения $(0,283))$. Аналогичные результаты получены для других рассматриваемых возрастных групп.

Нормальность распределения содержания пихтового масла в древесной зелени отдельных деревьев позволяет обоснованно применять статистические критерии Кохрена - для проверки гипотезы однородности дисперсий экспериментов и критерия Фишера - для проверки адекватности математической модели экспериментальным данным.

Применение критерия Кохрена показало, что гипотеза однородности дисперсий экспериментов (табл. 1) не отклоняется при 5\% уровне значимости (расчетное значение $(0,205)$ меньше критического значения (0,266)). Точность экспериментов оценивалась дисперсией воспроизводимости $\mathrm{SBc}^{2}=0,110$ с числом степеней свободы fвc $=81$. Ошибка воспроизводимости экспериментов $\mathrm{SBc}=0,33$.

Для описания возрастной динамики содержания пихтового масла принята модификация предложенной в [23] математической модели

$$
\frac{d^{2} Y(t)}{d t^{2}}+2 \times b \times \frac{d Y(t)}{d t}=b \times(A-Y(t))
$$

при начальных условиях $\mathrm{Y}(0)=\mathrm{y} 0, \mathrm{Y}^{\prime}(0)=\mathrm{y} 1$.

Решение дифференциального уравнения (1):

$$
Y(t)=a_{0}+\left(a_{1}+a_{2} \times t\right) \times e^{-b \times t},
$$

где $\mathrm{Y}(\mathrm{t})$ - содержание пихтового масла, \% к а.с.с.; $\mathrm{t}$ - возраст пихты, год; $(\mathrm{a}, \mathrm{b})$ - коэффициенты модели, $\mathrm{a}_{0}$ $=\mathrm{A}, \mathrm{a}_{1}=\mathrm{y} 0-\mathrm{A}, \mathrm{a}_{2}=\mathrm{y} 1+\mathrm{a}_{1} \times \mathrm{b}$.

Введя безразмерные переменные $\theta=\frac{Y-Y(0)}{A-Y(0)}, \theta 0=\frac{y 1}{b \times(A-Y(0))}, \tau=\frac{t}{T}$, где $T=\frac{1}{b}-$ постоянная времени, получим однопараметрическое дифференциальное уравнение

$$
\frac{d^{2} \theta(\tau)}{d \tau^{2}}+2 \times \frac{d \theta(\tau)}{d \tau}+\theta(\tau)=1, \theta(0)=0, \theta^{\prime}(0)=\theta 0
$$

решение которого определяется выражением

Ошибка! Объект не может быть создан из кодов полей редактирования.

\begin{tabular}{|c|c|c|c|c|}
\hline \multicolumn{2}{|c|}{ Возраст пихты, лет } & \multicolumn{3}{|c|}{ Содержания пихтового масла в древесной зелени, \% от а.с.с. } \\
\hline $\begin{array}{c}\text { Возрастная } \\
\text { группа }\end{array}$ & $\begin{array}{l}\text { Средний } \\
\text { возраст, } \mathrm{t}\end{array}$ & Среднее значение, Хс & $\begin{array}{c}\text { Дисперсия } \\
\text { эксперимента, S² }\end{array}$ & $\begin{array}{c}\text { Стандартная ошибка } \\
\text { среднего, Sc }\end{array}$ \\
\hline $4-7$ & 5,5 & 2,08 & 0,225 & 0,15 \\
\hline $15-20$ & 17,5 & 3,62 & 0,130 & 0,11 \\
\hline $17-22$ & 19,5 & 3,43 & 0,088 & 0,09 \\
\hline $27-35$ & 31,0 & 3,47 & 0,088 & 0,09 \\
\hline $55-65$ & 60,0 & 3,07 & 0,086 & 0,09 \\
\hline $85-.90$ & 87,5 & 2,26 & 0,071 & 0,08 \\
\hline $90-95$ & 92,5 & 2,39 & 0,085 & 0,09 \\
\hline $120-130$ & 125,0 & 1,87 & 0,130 & 0,11 \\
\hline $160-190$ & 175,0 & 1,63 & 0,086 & 0,09 \\
\hline
\end{tabular}

Таблица 1. Экспериментальные данные содержания пихтового масла в древесной зелени в зависимости от возраста Abies sibirica Ldb 


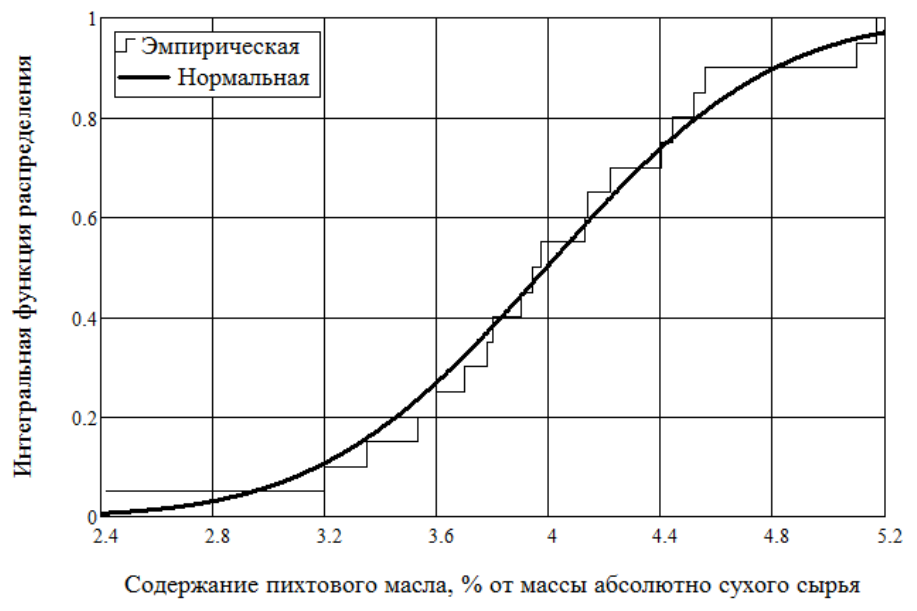

Максимальное значение
Рис. 1. Интегральная функция распределения пихтового масла в охвоенных побегах отдельных деревьев молодняка пихты

$$
\theta \max =\max (\theta(\tau))=1+(\theta 0-1) \times \exp (-\tau \max )
$$

соответствует

\section{Ошибка! Объект не может быть создан из кодов полей редактирования.}

Гипотеза адекватности модели экспериментальным данным не отвергается при 5\% уровне значимости (расчетное значение критерия Фишера $(2,29)$ меньше критического значения $(2,33)$ ). Стандартная ошибка модели $\mathrm{So}=0,16 \%$ к а.с.с., а коэффициент детерминации $\mathrm{R}^{2}=0,97$.

Результаты параметрической идентификации модели (1) - (2) нелинейным методом наименьших квадратов (МНК) и полученные методом имитационного моделирования МНК - оценки стандартных ошибок коэффициентов в области адекватности: $\mathrm{A}=\mathrm{a}_{0}=1,61 \pm 0,02 ; \mathrm{a}_{1}=-0,64 \pm 0,05 ; \mathrm{a}_{2}=0,232 \pm 0,003 ; \mathrm{b}=$ $0,0376 \pm 0,0004 ; \mathrm{T}=26,6 \pm 0,3 ; \mathrm{y} 0=0,97 \pm 0,04 ; \mathrm{y} 1=0,257 \pm 0,005 ; \theta 0=10,6 \pm 0,7 ; \tau \max =1,104 \pm 0,007$; $\theta \max =4,2 \pm 0,3, \operatorname{tmax}=29,4 \pm 0,2, \mathrm{Ymax}=3,7 \pm 0,2$.

Возрастная динамика содержания пихтового масла определяется выражениями

$$
\begin{gathered}
Y(t)=1,61+(0,232 \times t-0,64) \times \exp \left(\frac{-t}{26,6}\right) \\
\theta(\tau)=1+(9,63 \times \tau-1) \times \exp (-\tau), Y(\tau)=0,64 \times \theta(\tau)+0,97, \mathrm{t}=26,6 \times \tau
\end{gathered}
$$

МНК-оценка максимального содержания пихтового масла (3,66\% к а.с.с.) соответствует пихте 30 летнего возраста.

Учитывая ухудшение условий развития охвоенных побегов по мере приближениия к комлю (понижение температуры, освещенности, затенение), изучено влияние эндогенной изменчивости в верхней (табл. 2), средней (табл. 1) и нижней частях кроны (табл. 2).

При подъеме по стволу, соответствующему снижению возраста дерева, древесная зелень становится богаче эфирным маслом. В средней части кроны его содержится в 1,2, а в верхней - в 1,4 раза больше, чем в нижней.

Коэффициенты модели (1-2) для содержания пихтового масла в древесной зелени нижней и верхней частей кроны получены методом наименьших квадратов при предположении независимости $\mathrm{Y}(0)$ и $t_{\max }$ от места расположения древесной зелени в кроне. 
Таблица 2. Эндогенная изменчивость (по высоте кроны) содержания пихтового масла в древесной зелени от возраста Abies sibirica $L d b$.

\begin{tabular}{c|c|c}
\hline \multirow{2}{*}{ Возраст пихты, лет } & \multicolumn{2}{|c}{ Содержания пихтового масла в древесной зелени, \% от а.с.с. } \\
\cline { 2 - 3 } & Нижняя часть кроны & Верхняя часть кроны \\
\hline 25 & $3,12 \pm 0,04$ & $4,32 \pm 0,06$ \\
45 & $2,94 \pm 0,05$ & $4,02 \pm 0,08$ \\
130 & $1,65 \pm 0,06$ & $2,13 \pm 0,06$ \\
\hline
\end{tabular}

На рисунке 2 представлены результаты экспериментов и оптимальные МНК-оценки содержания эфирного масла в древесной зелени нижней, средней в верхней части кроны пихты, произрастающей в восточной и западной части Красноярской лесостепи в процессе онтогенеза. В результате анализа экспериментальных данных предложена зависимость для оценки содержания эфирного масла в древесной зелени охвоенных побегов по высоте кроны:

$$
\frac{d Y(t, h)}{d h}=\frac{k(t, h)}{H} \times Y(t, h), \text { или } Y(t, h)=Y(t, 0) \times \exp \left(\frac{\int_{0}^{h} k(t, x) d x}{H}\right),
$$

где $\mathrm{Y}(\mathrm{t}, \mathrm{h})$ - содержание пихтового масла в древесной зелени в кроне на расстоянии $\mathrm{h}$ от ее нижней части, \% к а.c.c.; t - возраст пихты, год; Н - высота кроны, м; k(t,h) - безразмерный коэффициент модели.

При $\mathrm{k}(\mathrm{t}, \mathrm{h})=\mathrm{k}(\mathrm{t})$ :

$$
Y(t, h)=Y(t, 0) \times \exp \left(\frac{k(t) \times h}{H}\right) .
$$

При $\mathrm{k}(\mathrm{t})=0,054$ - коэффициент детерминации модели (9) $\mathrm{R}^{2}=0,98$.

Полученные результаты позволяют оценить суммарное содержание пихтового масла в кроне дерева определенного возраста.

В таблице 3 представлены характеристики модели содержания эфирного масла в древесной зелени пихты, произрастающей в восточной и западной части Красноярской лесостепи (по данным таблиц $1-2$ ) и Лесосибирском регионе (по данным [26]), находящемся на 275 км севернее лесостепи. Расчеты подтвердили адекватность математических моделей (1) при уровне значимости $\alpha=0,05$.

Результаты экспериментов [26] и оптимальные МНК-оценки содержания эфирного масла в древесной зелени пихты, произрастающей в Лесосибирском регионе, в процессе онтогенеза представлены на рисунке 3.

Полученные результаты свидетельствуют о существенном влиянии климатических условий на содержание пихтового масла. Хотя для древостоев Abies sibirica Ldb. Красноярской лесостепи и Лесосибирского региона максимальное содержание пихтового масла соответствует деревьям 30-летнего возраста, для пихты, произрастающей в Лесосибирском регионе, наблюдается более высокое его содержание (в 1,3 раза выше для пихты 30-летнего возраста и старше).

Рис. 2. Содержание эфирного масла в древесной зелени пихты, произрастающей в восточной и западной частях Красноярской лесостепи, в зависимости от возраста дерева

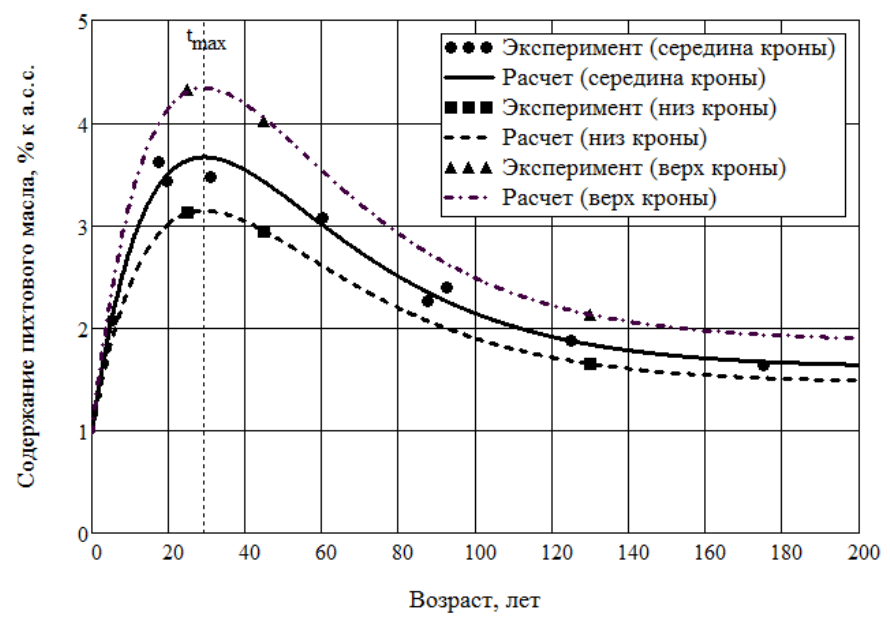


Таблица 3. Характеристики модели содержании эфирного масла в древесной зелени Abies Sibirica Ldb., произрастающей в восточной и западной частях Красноярской лесостепи и Лесосибирском регионе (по данным [26]), в зависимости от возраста пихты

\begin{tabular}{l|c|c|c|c|c|c|c|c|c|c}
\hline \begin{tabular}{c} 
Расположение ДЗ \\
\multicolumn{1}{c|}{ в кроне }
\end{tabular} & $\mathrm{a}_{0}$ & $\mathrm{a}_{1}$ & $\mathrm{a}_{2}$ & $\mathrm{~T}$ & $\mathrm{t}_{\max }$ & $\mathrm{Y}_{\max }$ & $\mathrm{Y} 0$ & $\mathrm{Y} 1$ & So & $\mathrm{R}^{2}$ \\
\hline Нижня часть* & 1,5 & $-0,5$ & 0,19 & 26,7 & 29 & 3,1 & 1,0 & 0,21 & 0,01 & 0,99 \\
Средняя часть* & 1,6 & $-0,6$ & 0,23 & 26,6 & 29 & 3,7 & 1,0 & 0,26 & 0,16 & 0,97 \\
Верхняя часть* & 1,9 & $-0,9$ & 0,29 & 26,2 & 29 & 4,3 & 1,0 & 0,32 & 0,03 & 0,99 \\
Нижняя часть** & 1,2 & 1,8 & 0,14 & 41,7 & 29 & 4,1 & 3,0 & 0,10 & 0,43 & 0,95 \\
Средняя часть** & 1,8 & 1,2 & 0,23 & 34,0 & 29 & 5,1 & 3,0 & 0,19 & 0,43 & 0,95 \\
Верхняя часть** & 2,2 & 0,8 & 0,29 & 31,5 & 29 & 5,9 & 3,0 & 0,27 & 0,43 & 0,95 \\
\hline
\end{tabular}

*-Красноярская лесостепь; **- Лесосибирский регион; ДЗ - древесная зелень

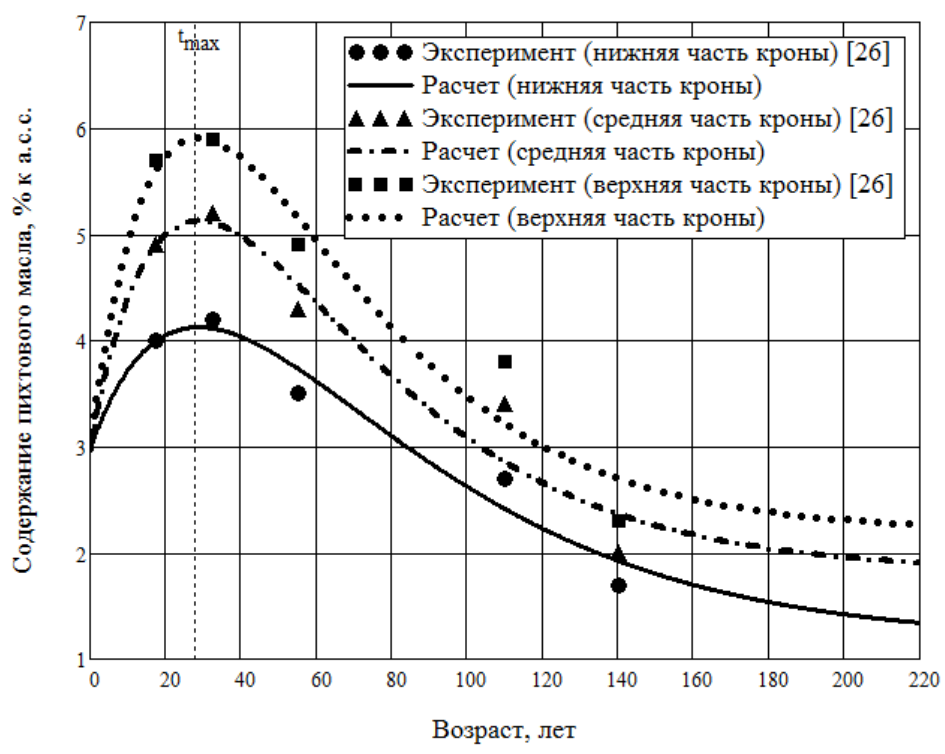

Рис. 3. Содержание эфирного масла в древесной зелени пихты, произрастающей в Лесосибирском регионе, в зависимости от возраста дерева

\section{Выводы}

Проведенные исследования свидетельствуют о существенном варьировании в ходе онтогенеза вклада эфирного масла в древесной зелени Abies sibirica Ldb. Максимальное содержание эфирного масла соответствует жерднякам, минимальное - перестойным древостоям. При старении дерева снижается и содержание в масле борнилацетата (от 34 до 24\%), которым определяется его качество и стоимость. Предложены адекватные экспериментальным данным математические модели возрастной динамики содержания эфирного масла в древесной зелени по высоте кроны. Проведена параметрическая идентификация модели для пихты, произрастающей в восточной и западной частях Красноярской лесостепи и в Лесосибирском регионе. Показано, что климатические условия оказывают существенное влияние на содержание пихтового масла. По сравнению с Красноярской лесостепью в более северном Лесосибирском регионе его содержание в 1,3 раза выше для пихты 30-летнего возраста и старше.

\section{Список литературь}

1. Александрова Н., Нехочина Т., Посульный Р. ЛПК России: цифры, тенденции, прогнозы // Русские товары Сибирь. Красноярск, 2007. №8 (47). С. 18-23.

2. Ягодин В.И. Основы безотходной технологии древесной зелени // Основы химической технологии древесного сырья. СПб., 2000. С. 50-58.

3. Ушанова В.М., Ушанов С.В., Репях С.М. Состав и переработка древесной зелени и коры пихты сибирской. Красноярск, 2008. 257 с.

4. Ушанова В.М. Комплексная переработка древесной зелени и коры пихты сибирской с получением продуктов, обладающих биологической активностью : автореф. дис. ... д-ра тех. наук. Красноярск, 2012. 34 с.

5. Лобанов В.В., Лобанова В.Э., Степень Р.А. Комплексная переработка древесной зелени в условиях малого пихтоваренного производства. Красноярск, 2007. 144 с. 
6. Ушанова В.М., Ушанов С.В. Экстрагирование древесной зелени и коры пихты сибирской сжиженным диоксидом углерода и водно-спиртовыми растворами. Красноярск, 2009. 191 с.

7. Степень Р.А., Невзоров В.Н., Невзорова Т.В. Организация производства пихтового масла. Красноярск, 2000. $103 \mathrm{c}$.

8. Степень Р.А. Утилизация древесных отходов. Пихтоварение. Красноярск, 2015. 162 с.

9. Осмоловская Н.А., Паршикова В.Н., Степень Р.А. Влияние биоценотических и технологических факторов на выход и состав кедрового масла // Химия растительного сырья. 2001. №4. С. 97-102.

10. Степень Р.А., Репях С.М. Летучие терпеноиды сосновых лесов. Красноярск, 1998. 406 с.

11. Ушанова В.М., Репях С.М. Углекислотные экстракты как источники биологически активных веществ. Красноярск, 2007. 156 с.

12. Ушанова В.М. Использование отходов пихты сибирской в альтернативных технологиях // Вестник Красноярского аграрного университета. 2010. №10. С. 182-186.

13. Ушанова В.М. Переработка древесной зелени и коры пихты сибирской с получением биологически активных продуктов // Хвойные бореальные зоны. 2013. Т. 30. №1-2. С. 138-142.

14. Степень Р.А. Изменение выхода и состава пихтового масла в процессе отгонки // Известия высших учебных заведений. Лесной журнал. 1998. №4. С. 114-119.

15. Паньков О.Г., Мирошниченко В.В., Паршикова В.Н., Степень Р.А. Выход и состав выделяемого различными способами пихтового масла // Химия растительного сырья. 2009. №3. С. 95-98

16. Ушанова В.М., Лебедева О.И., Девятловская А.Н. Основы научных исследований. Красноярск, 2004. 360 с.

17. Кобзарь А.И. Прикладная математическая статистика. М., 2006. 816 с.

18. Справочник по прикладной статистике: в 2 т. М., 1989. Т. 1.510 с.

19. Ушанов С.В. Параметрическая идентификация моделей. Красноярск, 2012. 202 с.

20. Ушанов С.В. Применение многомерных статистических методов при принятии решений. Красноярск, 2003. $239 \mathrm{c}$.

21. Ушанов С.В. Параметрическая идентификация моделей в MathCad. Ч. 1. Вычислительные эксперименты (многомерные нормально распределенные величины и линейные модели). Красноярск, 2015. 87 с.

22. Медведев С.О., Степень Р.А. Особенности качественных характеристик продуктов переработки древесной зелени северных регионов // Химия растительного сырья. 2013. №4. С. 184-187.

23. Репях С.М., Ушанова В.М., Ушанов С.В. Моделирование возрастной, сезонной и суточной динамики содержания эфирного масла в древесной зелени сосны обыкновенной // Химия растительного сырья. 2000. №1. C. $43-49$.

24. Степень Р.А., Климова Л.С. Содержание и состав терпеновых компонентов эфирного масла отдельных частей сосны обыкновенной // Химия древесины. 1985. №4. С. 184-187.

25. Орлов В.Я. Динамика массы хвои в сосновых культурах // Лесоведение. 1980. №11. С. $34-41$.

26. Медведев С.О. Влияние возраста и размещения в кроне древесной зелени на выход липидов и пихтового масла пихты Лесосибирского региона // Химия растительного сырья. 2011. №3. С. 133-136.

Поступило в редакиию 27 августа 2016 г.

После переработки 19 октября 2016 г.

Ushanov S.V., Stepen R.A., Ushanova V.M.* AGE-SPECIFIC DYNAMICS OF THE OIL COMPOSITION IN THE WOODY GREENERY OF ABIES SIBIRICA. THEORETICAL ASPECTS OF EVALUATION

Siberian State Technological University, pr. Mira, 82, Krasnoyarsk, 660049 (Russia), e-mail: ushanova_vm@mail.ru

Evaluated the variability of the content of essential oil in wood Siberian fir greenery in 9 age groups. It is shown, that except for the regrowth of forest regeneration measures its content to any perestojnym is reduced by half. Content in essential oil bornilacetata that determines the quality and price of the product, is reduced from 34 to $24 \%$. When you change the latitude growing Siberian fir (from Krasnoyarsk forest-steppe at taiga Lesosibirsk) its contents in wood greenery increases. Found a significant change in the content of essential oil in ohvoennyh shoots to the height of the tree crown. Its content at the top of the Crown in 1,5 times higher than the lower part. Offered dependency change in the content of essential oil in ohvoennyh shoots to the height of the tree crown. Received adequate model of age-related changes of the content of essential oil in ohvoennyh shoots, to assess the contribution and the nature of decreasing of essential oil in the assimiljacionnom apparatus of the Siberian fir in the age interval from 0 to 200 years. Held parametric identification model for Siberian fir growing in Krasnoyarsk forest and the Lesosibirsk region. The maximum content of essential oil from the Siberian fir corresponds from 25 to 30 years and then declining to a minimum at overaged trees.

Keywords: Abies, age, woody greenery, ethereal oil, mathematic modelling, statistics testing.

\footnotetext{
${ }^{*}$ Corresponding author.
} 


\section{References}

1. Aleksandrova N., Nekhochina T., Posul'nyi R. Russkie tovary - Sibir'. [Russian goods - Siberia]. Krasnoiarsk, 2007, no. 8 (47), pp. 18-23. (in Russ.).

2. Iagodin V.I. Osnovy khimicheskoi tekhnologii drevesnogo syr'ia. [Fundamentals of chemical technology of wood raw material]. St. Petersburg, 2000, pp. 50-58. (in Russ.).

3. Ushanova V.M., Ushanov S.V., Repiakh S.M. Sostav i pererabotka drevesnoi zeleni i kory pikhty sibirskoi. [The composition and processing of green wood and bark of Siberian fir]. Krasnoiarsk, 2008, 257 p. (in Russ.).

4. Ushanova V.M. Kompleksnaia pererabotka drevesnoi zeleni i kory pikhty sibirskoi s polucheniem produktov, obladaiushchikh biologicheskoi aktivnost'iu: avtoref. dis. ... dokt. tekh. nauk. [Complex processing of wood greens and Siberian fir bark to give products having biological activity: Author. Dis. ... Doctor. technical Sciences]. Krasnoiarsk, 2012, 34 p. (in Russ.).

5. Lobanov V.V., Lobanova V.E., Stepen' R.A. Kompleksnaia pererabotka drevesnoi zeleni v usloviiakh malogo pikhtovarennogo proizvodstva. [Complex processing of wood greens in a small production pihtovarennogo]. Krasnoiarsk, 2007, 144 p. (in Russ.).

6. Ushanova V.M., Ushanov S.V. Ekstragirovanie drevesnoi zeleni i kory pikhty sibirskoi szhizhennym diok-sidom ugleroda i vodno-spirtovymi rastvorami. [Extraction of green wood and bark of Siberian fir liquefied carbon dioxide and water-alcohol solutions]. Krasnoiarsk, 2009, 191 p. (in Russ.).

7. Stepen' R.A., Nevzorov V.N., Nevzorova T.V. Organizatsiia proizvodstva pikhtovogo masla. [Pine oil production Organization]. Krasnoiarsk, 2000, 103 p. (in Russ.).

8. Stepen' R.A. Utilizatsiia drevesnykh otkhodov. Pikhtovarenie. [Utilization of wood waste. Pihtovarenie]. Krasnoiarsk, 2015, 162 p. (in Russ.).

9. Osmolovskaia N.A., Parshikova V.N., Stepen' R.A. Khimiia rastitel'nogo syr'ia, 2001, no. 4, pp. 97-102. (in Russ.).

10. Stepen' R.A., Repiakh S.M. Letuchie terpenoidy sosnovykh lesov. [The volatile terpenoids pine forests]. Krasnoiarsk, 1998, 406 p. (in Russ.).

11. Ushanova V.M., Repiakh S.M. Uglekislotnye ekstrakty kak istochniki biologicheski aktivnykh veshchestv. [Carbon dioxide extracts as a source of biologically active substances]. Krasnoiarsk, 2007, 156 p. (in Russ.).

12. Ushanova V.M. Vestnik Krasnoiarskogo agrarnogo universiteta, 2010, no. 10, pp. 182-186. (in Russ.).

13. Ushanova V.M. Khvoinye boreal'nye zony, 2013, vol. 30, no. 1-2, pp. 138-142. (in Russ.).

14. Stepen' R.A. Izvestiia vysshikh uchebnykh zavedenii. Lesnoi zhurnal, 1998, no. 4, pp. 114-119. (in Russ.).

15. Pan'kov O.G., Miroshnichenko V.V., Parshikova V.N., Stepen' R.A. Khimiia rastitel'nogo syr'ia, 2009, no. 3, pp. 95-98. (in Russ.)

16. Ushanova V.M., Lebedeva O.I., Deviatlovskaia A.N. Osnovy nauchnykh issledovanii. [Basic scientific research] Krasnoiarsk, 2004, 360 p. (in Russ.).

17. Kobzar' A.I. Prikladnaia matematicheskaia statistika. [Applied Mathematical Statistics]. Moscow, 2006, 816 p. (in Russ.).

18. Spravochnik po prikladnoi statistike. [Applied Statistics Handbook], Moscow, 1989, vol. 1, 510 p. (in Russ.).

19. Ushanov S.V. Parametricheskaia identifikatsiia modelei. [Parametric identification of models]. Krasnoiarsk, 2012, 202 p. (in Russ.).

20. Ushanov S.V. Primenenie mnogomernykh statisticheskikh metodov pri priniatii reshenii. [The use of multivariate statistical methods in decision-making]. Krasnoiarsk, 2003, 239 p. (in Russ.).

21. Ushanov S.V. Parametricheskaia identifikatsiia modelei v MathCad. Chast' 1. Vychislitel'nye eksperimenty (mnogomernye normal'no raspredelennye velichiny i lineinye modeli). [Parametric identification of models in MathCad. Part 1. Computational experiments (multivariate normal distribution and magnitude of linear models)]. Krasnoiarsk, 2015, 87 p. (in Russ.).

22. Medvedev S.O., Stepen' R.A. Khimiia rastitel'nogo syr'ia, 2013, no. 4, pp. 184-187. (in Russ.).

23. Repiakh S.M., Ushanova V.M., Ushanov S.V. Khimiia rastitel'nogo syr'ia, 2000, no. 1, pp. 43-49. (in Russ.).

24. Stepen' R.A., Klimova L.S. Khimiia drevesiny, 1985, no. 4, pp. 184-187. (in Russ.).

25. Orlov V.Ia. Lesovedenie, 1980, no. 11, pp. 34-41. (in Russ.).

26. Medvedev S.O. Khimiia rastitel'nogo syr'ia, 2011, no. 3, pp. 133-136. (in Russ.). 